\title{
Chimeric Antigen Receptor T-Cell Therapy
}

\author{
Azgar Abdul Rasheed ${ }^{1}$ Venkata Pradeep Babu Koyyala²
}

${ }^{1}$ Department of Medical Oncology, Dr. BRA IRCH, AIIMS, New Delhi, India

${ }^{2}$ Department of Medical Oncology, Rajiv Gandhi Cancer Institute and Research Centre, New Delhi, India

Ind J Med Paediatr Oncol 2021;42:89-92.

The beginnings of "Immunotherapy" can arguably be traced back to the ancient Egyptians. They, like James Paget, Wilhelm Busch, and Friedrich Fehleisen in the mid-1800s, observed that some cancer patients experienced tumor regression after suffering from infections. By the late 1800s, the "Father of Immunotherapy" William Coley had started administering injections composed of dead Streptococcus pyogenes and Serratia marcescens as a crude form of immunotherapy. His work was carried forward by his daughter, Helen Coley Nauts, and eventually, Lloyd Old. Old worked on the antitumor effects of the Bacillus Calmette-Guérin vaccine and earned the title "Father of Modern Cancer Immunology." Today, the domain of immunotherapy has delivered several new armaments in the war against cancer. These include targeted therapies using monoclonal antibodies, cytokine therapy (interferon- $\alpha[\mathrm{IFN}-\alpha]$ and interleukin-2 [IL-2]), immune checkpoint inhibitors (anti-CTLA-4, anti-PD1, and anti-PD-L1), oncolytic viruses (T-Vec/talimogene laherparepvec), cancer vaccines, immune costimulatory molecules, and adoptive cell therapy (ACT). Founded at the cross-roads of genetic engineering and molecular biology, ACT can be of various types: tumor-infiltrating lymphocyte (TIL) therapy, T-cell receptor (TCR)-engineered T-cell therapy, natural killer cell therapy, or chimeric antigen receptor (CAR) T-cell therapy. Among these, CAR T-cells have received the most attention and shown the most promise.

In TIL therapy, TILs are extracted from a patient's tumor biopsy specimen and then cocultured with autologous dendritic cells exposed to neoantigens present in the patient's tumor. TILs recognizing the patient-specific neoantigens are then selected, expanded in vitro using IL-2, and then infused back into the patient. TIL therapy has shown some promise in melanomas, colorectal cancer, and breast cancer. TCR T-cell therapy is less invasive than TIL therapy as the required lymphocytes are sourced from the patient's peripheral blood and are more proliferative than TILs. After extraction, purification, and activation, the T-cells are
Address for correspondence Venkata Pradeep Babu Koyyala, MD, DNB Medical Oncology, Department of Medical, Oncology, Rajiv Gandhi Cancer, Institute and Research Centre,110085 New Delhi,India (e-mail: pradeepbabu.koyyala@gmail.com).

genetically modified by retroviral/lentiviral transduction or nonviral methods (such as electroporation or transposon delivery systems) to express cell-surface receptors targeting specific antigens. These are still natural receptors and can detect antigens from anywhere in the cell, as long as they are presented to them by the major histocompatibility complex (MHC) molecules. Trials have shown some benefit in sarcomas and melanomas. However, they can only target peptide antigens and, to be effective, require adequate MHC expression by the patient's tumor cells. TCRs may also cross-react with endogenous antigens and, hence, carry a risk of induced severe autoimmunity. The more advanced CAR T-cells have the advantage that they are not MHC restricted and can recognize both protein and nonprotein antigens independently of the MHC, without antigen processing/presentation by the target cells. Thus, they can be engineered against a wider array of targets. The "chimeric" in CARs refers to the fact that these combine both antigen-binding and T-cell activation functions into a single synthetic receptor. The antigen binding in CAR T-cells is achieved through the use of specific recombinant antibodies in the extracellular domain, earning them the nickname "T-bodies." Just like TILs, TCR and CAR T-cells are also clonally expanded in vitro and, then, after subjecting the patient to a lymphodepleting chemotherapy, infused back into the patient, often with in vivo IL-2 support. The steps involved in CAR T-cell therapy are shown in - Fig. 1.

"Immunotherapy" was the ASCO "Advance of the Year" in 2016 and 2017, and in 2018, the honor went to CAR T-cell research. Yet, the work had started much earlier, with Zelig Eshhar proposing the concept in the early 1980s and, subsequently, engineering the first CAR T-cell. First-generation CAR T-cells coupled an extracellular single-chain variable fragment (scFv) with an intracellular $\mathrm{CD} 3-\xi$, (zeta) signaling domain. A scFv should not be thought of as an antibody fragment; it is a fusion protein made by joining variable regions of light $\left(\mathrm{V}_{\mathrm{L}}\right)$ and heavy $\left(\mathrm{V}_{\mathrm{H}}\right)$ immunoglobulin chains with a peptide linker. Michel Sadelain was the first to conduct
DOI https://doi.org/ $10.1055 / \mathrm{s}-0041-1729437$ ISSN 0971-5851
(C) 2021. Indian Society of Medical and Paediatric Oncology This is an open access article published by Thieme under the terms of the Creative Commons Attribution-NonDerivative-NonCommercial-License, permitting copying and reproduction so long as the original work is given appropriate credit. Contents may not be used for commercial purposes, or adapted, remixed, transformed or built upon. (https://creativecommons.org/licenses/by-nc-nd/4.0/).

Thieme Medical and Scientific Publishers Pvt. Ltd. A-12, 2nd Floor, Sector 2, Noida-201301 UP, India 
clinical trials in this area and used second-generation CAR T-cells with additional co-signaling molecules such as 4-1BB or CD28. He called these cells "living drugs," capable of greater in vivo clonal expansion and longer persistence in circulation. In 2017, two CAR T-cell therapies received the Food and Drug Administration (FDA) approval-tisagenlecleucel and axicabtagene ciloleucel, both of which target CD19 (-Table 1). The evolution of CAR T-cell therapy is depicted in - Fig. 2.

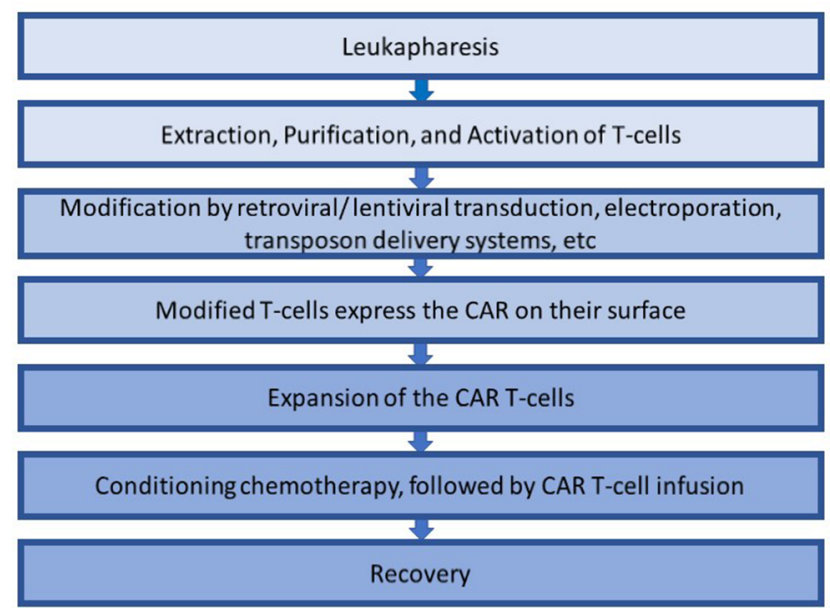

Fig. 1 Chimeric antigen receptor T-cell production. CAR, chimeric antigen receptor.

\section{Second-Generation Chimeric Antigen Receptor T-Cells}

Tisagenlecleucel (Kymriah, Novartis, Basel, Switzerland) has an anti-CD19 extracellular domain coupled with CD3- $\xi$ and $4-1 \mathrm{BB}$ intracellular signaling domains. The $4-1 \mathrm{BB}$ domain is thought to increase the persistence of CAR T-cells by countering T-cell exhaustion. It is approved in patients aged $<25$ years with B-cell precursor acute lymphoblastic leukemia (ALL) that is refractory to standard treatment or in second or later relapse ${ }^{1}$ and adults with $\mathrm{R} / \mathrm{R}$ large B-cell lymphoma post $>2$ lines of systemic therapy. ${ }^{2}$ Due to the risk of cytokine release syndrome (CRS) and neurotoxicities, the FDA approval was conditional on the basis of approved Risk Evaluation and Mitigation Strategies, which includes having a minimum of two doses of tocilizumab available for each patient for immediate administration.

Axicabtagene ciloleucel (Yescarta, Kite Pharma, Los Angeles, California, USA Inc.) is an anti-CD19, with a CD28 co-stimulatory domain. Axi-cel has received the FDA approval for treating adults with relapsed/refractory large B-cell lymphoma after two or more lines of systemic therapy, including diffuse large B-cell lymphoma (DLBCL)-not otherwise specified, primary mediastinal large B-cell lymphoma, high-grade B-cell lymphoma, and DLBCL arising from follicular lymphoma. ${ }^{3}$

Next on the horizon for the FDA approval is the CD19-targeted, 4-1BB CAR T-cell product lisocabtagene

Table 1 Food and Drug Administration-approved chimeric antigen receptor T-cell therapies

\begin{tabular}{|c|c|c|c|}
\hline Name & $\begin{array}{l}\text { Tisagenlecleucel (Kymriah, } \\
\text { Novartis) }\end{array}$ & & $\begin{array}{l}\text { Axicabtagene ciloleucel (Yescarta, } \\
\text { Kite Pharma, Inc.) }\end{array}$ \\
\hline CAR & \multicolumn{2}{|c|}{ Anti-CD19 with 4-1BB costimulatory domain } & $\begin{array}{l}\text { Anti-CD19 with CD28 costimulatory } \\
\text { domain }\end{array}$ \\
\hline \multirow[t]{2}{*}{ Indications } & Patients aged $\leq 25$ years with B-cell & R/R large B-cell lymphoma post & Adults with relapsed/refractory large \\
\hline & $\begin{array}{l}\text { Precursor ALL refractory to standard } \\
\text { treatment or in second or later relapse }\end{array}$ & $\geq 2$ lines of systemic therapy & $\begin{array}{l}\text { B-cell lymphoma after two or more } \\
\text { lines of systemic therapy, including } \\
\text { DLBCL-NOS, PMBCL, high-grade B-cell } \\
\text { lymphoma, and DLBCL arising from FL }\end{array}$ \\
\hline $\begin{array}{l}\text { Approval } \\
\text { based on }\end{array}$ & $\begin{array}{l}\text { Phase II JULIANA trial in } 75 \text { children and } \\
\text { young adults with CD19+ relapsed or } \\
\text { refractory B-cell ALL }\end{array}$ & Single-arm Phase II JULIET trial & $\begin{array}{l}\text { Phase II of the ZUMA-1 trial, involving } \\
101 \text { patients with DLBCL, PMBCL, or } \\
\text { transformed FL with refractory disease }\end{array}$ \\
\hline Outcome & $\begin{array}{l}\text { The overall remission rate at } 3 \text { months } \\
\text { was } 81 \% \text {, and all those who responded } \\
\text { had no detectable MRD as determined } \\
\text { by flow cytometry } \\
\text { At } 12 \text { months, the EFS was } 50 \%(95 \% \mathrm{Cl} \text { : } \\
35,64) \text { and OS was } 76 \%(95 \% \mathrm{Cl}: 63,86) \\
\text { The median duration of remission was } \\
\text { not reached } \\
\text { Tisa-cel was found to persist in } \\
\text { the blood even at } 20 \text { months after } \\
\text { administration }\end{array}$ & $\begin{array}{l}\text { Overall response rate of } 52 \% \\
\text { ( } 95 \% \mathrm{Cl}: 41-62) ; 40 \% \text { had } \\
\text { CR and } 12 \% \text { had PR } \\
\text { At } 12 \text { months after the initial } \\
\text { response, estimated RFS was } 65 \% \text {. } \\
\text { At } 12 \text { months, RFS was } 79 \% \text { among } \\
\text { patients who had achieved a CR }\end{array}$ & $\begin{array}{l}\text { ORR of } 82 \% \text { and CR rate of } 54 \% \text { OS at } \\
18 \text { months was } 52 \%\end{array}$ \\
\hline Toxicities & $\begin{array}{l}73 \% \text { of patients had Grade } 3 / 4 \text { adverse } \\
\text { events. } 77 \% \text { of patients experienced } \\
\text { CRS and } 20 \% \text { had neurological toxicities }\end{array}$ & $\begin{array}{l}\text { The most common Grade } 3 / 4 \text { adverse } \\
\text { events were CRS ( } 22 \%) \text {, neurologic } \\
\text { toxicities ( } 12 \%) \text {, cytopenias ( } 32 \%) \text {, } \\
\text { infections }(20 \%) \text {, and febrile neutro- } \\
\text { penia }(14 \%)\end{array}$ & $\begin{array}{l}\text { Grade } 3 / 4 \text { adverse events were recorded } \\
\text { in } 95 \% \text {, including Grade } 3 / 4 \text { CRS in } 13 \% \\
\text { and Grade } 3 / 4 \text { neurological events in } \\
28 \%\end{array}$ \\
\hline
\end{tabular}

Abbreviations: CRS, cytokine release syndrome; CAR, chimeric antigen receptor; OS, overall survival; $\mathrm{Cl}$, confidence interval; MRD, measurable residual disease; EFS, event-free survival; ORR, objective response rate; CR, complete response; PMBCL, primary mediastinal large B-cell lymphoma, FL, follicular lymphoma; DLBCL-NOS, diffuse large B-cell lymphoma-not otherwise specified; ALL, acute lymphoblastic leukemia; RFS, relapse-free survival; PR, partial response. 


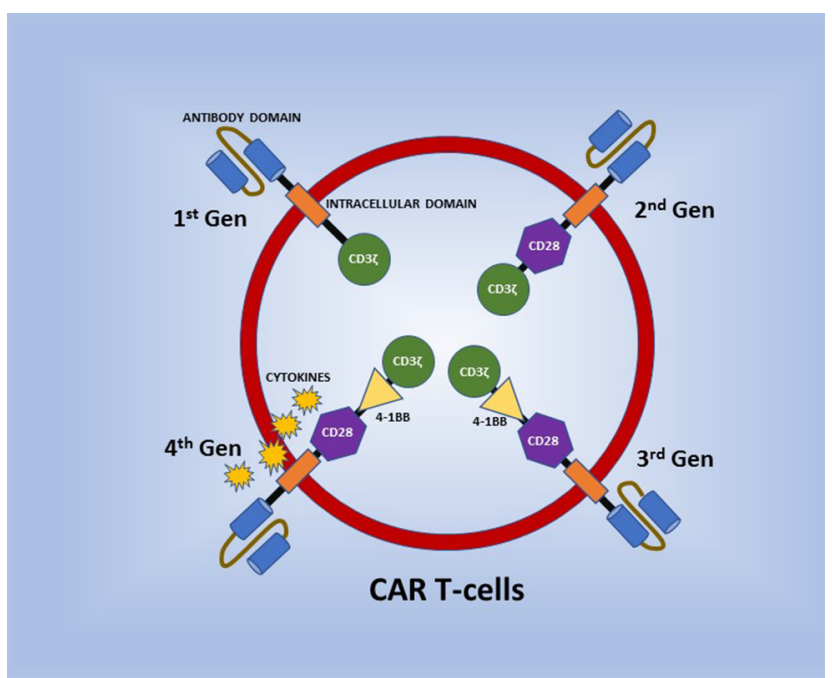

Fig. 2 Evolution of chimeric antigen receptor T-cell therapy. CAR, chimeric antigen receptor.

maraleucel (Lisa-cel, Juno Therapeutics/Bristol-Myers Squibb). Lisa-cel has shown a $53 \%$ complete response rate in relapsed/refractory large B-cell lymphoma post $>2$ lines of therapy. ${ }^{4}$

Durability of remissions has been an issue with CAR T cell therapy. Of the relapsed B-cell ALL patients who initially respond to anti-CD19-based therapy, around a third will eventually relapse. This is often due to a phenomenon called "antigen loss" where the malignant cells simply stop expressing the CD19 antigen. This may then respond to anti-CD22 CAR T-cell therapies. Some studies have used dual targets, such as CD19 and CD23 simultaneously, and these tandem CAR (TanCAR) designs have been found to prevent antigen loss. B-cell maturation agent-targeted CAR T-cells are being tested in multiple myeloma.

\section{Third- and Fourth-Generation Chimeric Antigen Receptor T-Cells}

Third-generation CAR T-cells have two tandem costimulatory domains, for example, both CD28 and 4-1BB, along with CD3- . CAR T-cells have not been successful in solid tumors because they do not express cell-surface antigens to the extent found in hematological malignancies. Trials targeting mesothelin in lung/pancreatic cancers and epidermal growth factor receptor in glioblastomas have failed. The immunosuppressive tumor microenvironments inherent in solid cancers have also been found to be troublesome. To address this issue, fourth-generation CAR T-cells known as T-cells redirected for universal cytokine killing are being studied. These "armored" Vsupef CAR T-cells are engineered to secrete cytokines (such as the pro-inflammatory IL-12/IL-15/IL-18) or directly interact with innate immune cells (such as dendritic cells, macrophages, or regulatory T-cells) and to thereby modulate hostile tumor microenvironments.

\section{What Lies Ahead}

Off-the-shelf CAR T-cell therapies are also being tested. These are manufactured from healthy donors, not individual patients, and hence provide savings on cost and time. Cellectis has been manufacturing these using transcription activator-like effector nucleases for gene editing. In the future, nanotechnology may even enable the engineering of CAR T-cells within the body. Clustered regularly interspaced short palindromic repeats (CRISPR) gene-editing technology may permit greater precision in T-cell engineering. Sadelain et al utilized this technology to insert a CAR cassette specifically in the T-cell receptor $\alpha$-chain gene. ${ }^{6}$ These CRISPR-edited CAR T-cells are more effective than conventional CAR T-cells at killing malignant cells. They also suffer less "exhaustion," that is, they are less likely to stop recognizing and killing tumor cells with the passage of time. The CRISPR-Cas9 technique is also safer than the retroviral/lentiviral-mediated random insertion used in conventional CAR T-cells because it decreases the risk of creating harmful mutations. CAR T-cells may even come with inbuilt "off-switches" to protect against CRS. In February 2020, the FDA approved an investigational new drug application for such a "switchable" CAR T cell therapy being evaluated for use in non-Hodgkin lymphoma and chronic lymphocytic leukemia.

\section{Toxicities}

The most significant toxicity of CAR T-cell therapy is CRS. It is characterized by a sudden flood of pro-inflammatory cytokines (IFN- $\gamma$, tumor necrosis factor- $\alpha$, IL-6, IL-10, etc.) leading to exaggerated and uncontrolled immune activation. This, in turn, causes fever, capillary leakage, hypotension, tachycardia, respiratory failure, and eventually, multiorgan dysfunction. CRS is an on-target, on-tumor toxicity, indicating that the infused T-cells are functioning as expected. In fact, the greater the disease burden and the T-cell dose infused, the higher the risk of CRS. Besides supportive care, The IL-6 receptor antagonist tocilizumab (Actemra) has become the standard drug for the treatment of CRS. The American Society for Transplantation and Cellular Therapy Consensus grading of $\mathrm{CRS}^{5}$ and the appropriate treatment for each grade are shown in - Table 2. Steroids are usually reserved for severe CRS due to concerns that steroid therapy may deplete the infused CAR T-cells, although this has not been proven to occur. Then, there are on-target, off-tumor toxicities that occur due to the CAR T-cells attacking normal cells that express the target antigen. For example, this can manifest as B-cell aplasia and hypogammaglobulinemia, due to the CAR T-cells attacking normal B-cells carrying the CD19 antigen. This is partially compensated for by immunoglobulin transfusions. Other common side effects include tumor lysis syndrome, anaphylaxis, and neurological toxicities such as immune effector cell-associated neurotoxicity syndrome. 
Table 2 Grading and treatment of cytokine release syndrome

\begin{tabular}{|c|c|c|}
\hline Grade & Criteria & Management \\
\hline Grade 1 & Fever $\geq 38^{\circ} \mathrm{C}$ not attributable to any other cause & \multirow{2}{*}{$\begin{array}{l}\text { For mild CRS, } \\
\text { Symptomatic Treatment } \\
\text { plus } \\
\text { Product-specific Risk Evaluation and } \\
\text { Mitigation Strategies (REMS) }\end{array}$} \\
\hline Grade 2 & $\begin{array}{l}\text { Fever } \geq 38^{\circ} \mathrm{C} \text { plus } \\
\text { hypotension not requiring vasopressors OR hypoxia requiring low-flow } \\
\text { oxygen ( } \leq 6 \mathrm{~L} / \mathrm{min})\end{array}$ & \\
\hline Grade 3 & $\begin{array}{l}\text { Fever } \geq 38^{\circ} \mathrm{C} \text { plus } \\
\text { hypotension requiring one vasopressor } \mathrm{OR} \\
\text { hypoxia requiring high-flow oxygen by nasal cannula/ face-mask/Venturi } \\
\text { mask }\end{array}$ & \multirow{2}{*}{$\begin{array}{l}\text { For severe CRS, } \\
\text { Tocilizumab } \\
(<30 \mathrm{~kg}-12 \mathrm{mg} / \mathrm{kg}, \geq 30 \mathrm{~kg}-8 \mathrm{mg} / \\
\mathrm{kg} \text { ) IV over } 1 \text { hour q } 8 \mathrm{~h} \text { x maximum } 4 \\
\text { doses plus } \\
\text { Steroid Therapy } \\
\text { (Inj. Hydrocortisone } 100 \mathrm{mg} \text { IV q8h, } \\
\text { or methylprednisolone } 1 \mathrm{mg} / \mathrm{kg} / \text { day, } \\
\text { etc.) }\end{array}$} \\
\hline Grade 4 & $\begin{array}{l}\text { Fever } \geq 38^{\circ} \mathrm{C} \text { plus } \\
\text { hypotension requiring }>1 \text { vasopressors } \mathrm{OR} \\
\text { hypoxia requiring positive-pressure ventilation }\end{array}$ & \\
\hline
\end{tabular}

Abbreviations: CRS, cytokine release syndrome; CAR, chimeric antigen receptor; OS, overall survival; $\mathrm{Cl}$, confidence interval; MRD, measurable residual disease; EFS, event-free survival; ORR, objective response rate; CR, complete response; PMBCL, primary mediastinal large B-cell lymphoma, FL, follicular lymphoma; DLBCL-NOS, diffuse large B-cell lymphoma-not otherwise specified; ALL, acute lymphoblastic leukemia; RFS, relapse-free survival; PR, partial response.

Currently available CAR T-cell therapies cost hundreds of thousands of dollars in the United States. In India, many groups, including one from IIT Bombay, have been at work trying to deliver the technology here at a fraction of the price. Work is also ongoing for developing an indigenous CAR T-cell platform. Patients in India may possibly have access to T-cell therapy here by the end of this year.

\section{Financial Support and Sponsorship \\ Nil.}

\section{Conflicts of Interest}

There are no conflicts of interest.

\section{References}

1 Maude SL, Laetsch TW, Buechner J, et al. Tisagenlecleucel in children and young adults with B-cell lymphoblastic leukemia. N Engl J Med 2018;378(5):439-448
2 Schuster SJ, Bishop MR, Tam CS, et al. JULIET Investigators. Tisagenlecleucel in adult relapsed or refractory diffuse large B-cell lymphoma. N Engl J Med 2019;380(1):45-56

3 Neelapu SS, Locke FL, Bartlett NL, et al. Axicabtagene ciloleucel car T-cell therapy in refractory large B-cell lymphoma. N Engl J Med 2017;377(26):2531-2544

4 Abramson JS, Palomba ML, Gordon LI, et al. Pivotal safety and efficacy results from transcend NHL 001, a multicenter Phase 1 study of lisocabtagene maraleucel (liso-cel) in relapsed/ refractory (R/R) large B cell lymphomas. Blood 2019;134 (Suppl 1):241

5 Lee DW, Santomasso BD, Locke FL, et al. ASTCT consensus grading for cytokine release syndrome and neurologic toxicity associated with immune effector cells. Biol Blood Marrow Transplant 2019;25(4):625-638

6 Eyquem J, Mansilla-Soto J, Giavridis T, et al. Targeting a CAR to the TRAC locus with CRISPR/Cas9 enhances tumour rejection. Nature 2017;543:113-117 